Список литературы:

1. http://en.wikipedia.org/wiki/Adobe_Photoshop

2. http://ru.wikipedia.org/wiki/Adobe_Photoshop

3. http://window.edu.ru/catalog/pdf2txt/176/79176/59829?p_page=5

4. http://stockers.ru/articles/rastr/

5. http://ipic.su/blog/2010/11/17/rgb-cmyk-xyz

6. http://www.xserver.ru/computer/graphic/obsh/3/

7. http://www.compkursy.ru/photoshop/

\title{
Исследование стационарности низкочастотных микросейсмических сигналов пункта Удыль
}

Рябинкин К.С., Пупатенко В.В., Институт тектоники и геофизики им. Ю.А. Косыгина ДВО РАН, 2. Хабаровск E-mail: kostya-rowan@mail.ru

Научный руководитель: о.г.-м.н., профессор Трофименко С.В.

Изучены статистические параметры микросейсмических сигналов пункта Удыль, сделан вывод о несоответствии статистического распределения скоростей смещения нормалному. Установлен один из источников генерации микросейсм в диапазоне более 2 Гц. Проанализирована зависимость дисперсии микросейсмического сигнала от продолжительности интервала оценки. Выявлен участок относительной стабилизации дисперсии на коротких интервалах до 100 мин., в то время как при длительности в несколько часов дисперсия не стабилизируется.

В настоящей работе для изучения статистических параметров микросейсмических сигналов используются записи микросейсм, полученных во время полевых сейсмических наблюдений вблизи оз. Удыль (Ульчский p-н Хабаровского края). Сейсмические наблюдения проводились в течение десяти дней с 23 июля по 1 августа 2014 г цифровым регистратором с непрерывной записью REF TEK-130, оснащённым широкополосным сейсмометром REF TEK 150-120. Основная задача данных исследований - изучение строения земной коры.

Уровень микросейсмического шума в районе пункта наблюдений (рис. 1) невысокий. На рис. 1 кривые спектральной плотности мощности (СПМ) для Xканала (ориентированного на север) соответствуют значениям вероятности 5, 50 и 95\% за всё время наблюдений. Также приведены модели низкого (NLNM) и высокого (NHNM) шума [13]. На всём рассмотренном диапазоне периодов (0.1-10 c) медианный уровень микросейсмического шума ближе к NLNM, чем к NHNM. 


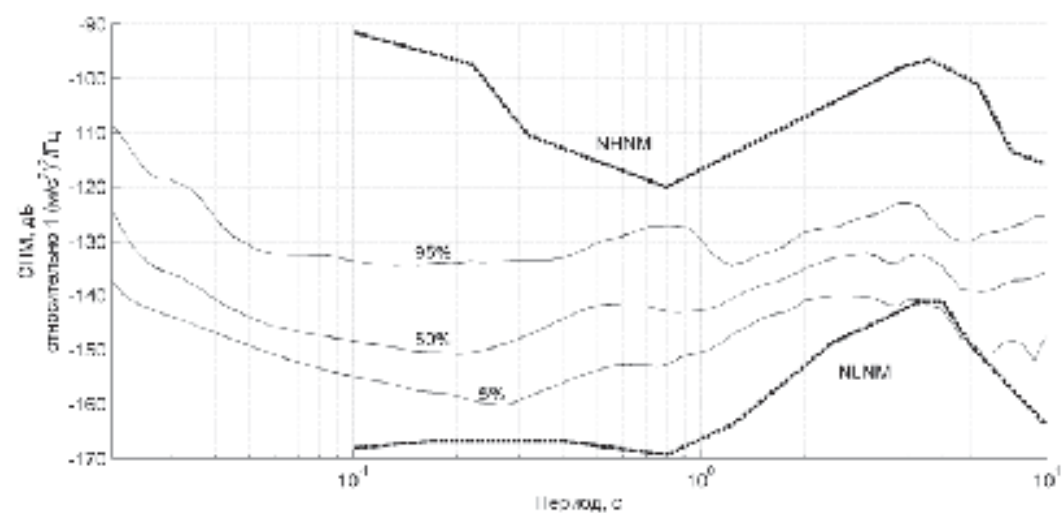

Рис. 1. Спектральные плотности мощности для X-канала, соответствующие значениям вероятности 5, 50 и 95\%, а также модели шума NLNM и NHNM

Микросейсмическое поле можно представить в виде суммы случайной функции и детерминированного сигнала. Для использования детерминированной компоненты низкочастотных микросейсм необходимо детальное изучение статистических свойств микросейсм в пространстве и времени. Как правило, для анализа используются частоты и амплитуды пиков в микросейсмических спектрах в предположении их связи с пространственными параметрами залегания геологических слоев [2]. Наши исследования показывают, что спектральный состав микросейм отличается в каждой точке наблюдений [3-6, 9].

Анализ статистических распределений скорости смещений в микросейсмическом сигнале в пункте Удыль (рис. 2) показывает, что они очень сильно расходятся с нормальным. Например, для Х-компоненты (рис. 2) были определены следующие оценки параметров распределения: эксцесс 1,474 $\pm 0,001$ (эксцесс нормального

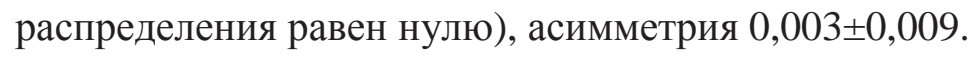
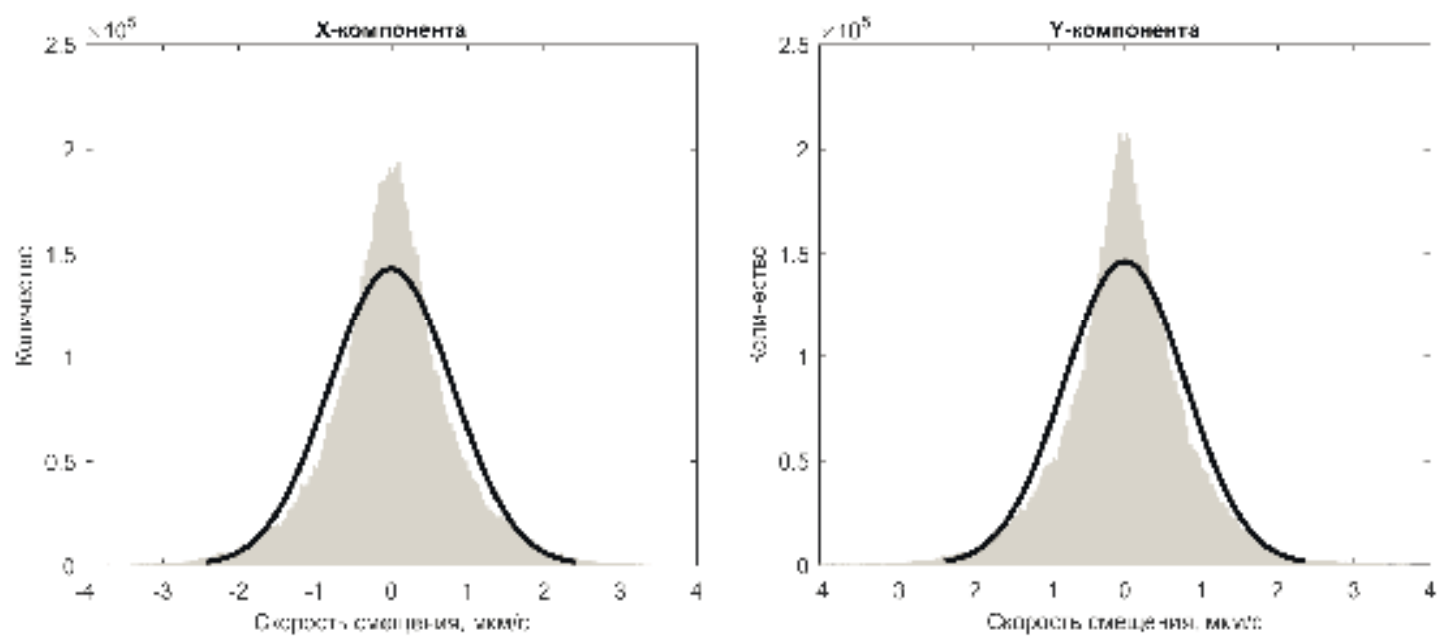

Рис. 2. Гистограммы скорости смещения в микросейсмическом сигнале (0.03-15 Гц) и соответствующие им нормальные распределения (чёрные линии)

Для геологической интерпретации данных об амплитуде и спектральном составе микросейсм необходимо, чтобы эти данные были стационарны $[1,2]$. Под стационарностью понимается независимость от времени и от внешних условий, в том числе метеорологических. Хотя на практике такая проверка неосуществима, она 
может быть проведена, если принять ряд допущений [2], на основе которых формулируются практические критерии стационарности [6-8].

Одной из причин генерации низкочастотных микросейсм является передача вариаций давления непосредственно на твердую поверхность [Beauduin, 1996]. Для проверки этого положения было проанализировано изменение во времени среднего значения СПМ на частотах 2-16 Гц (рис. 3, А). Значения СПМ были рассчитаны через каждые две минуты, после чего применением скользящего медианного фильтра были исключены вариации короче 80 минут. За тот же временной интервал был построен график изменения скорости ветра на ближайшей метеостанции (рис. 3, Б).

Некоторые временные отрезки повышенного уровня шума совпадали с повышением силы ветра. Между средним значением СПМ и скоростью ветра существует умеренная корреляционная зависимость (коэффициент корреляции составил 0,396). Сходный эффект был отмечен, например, в работе [12]. Таким образом, даже после исключения коротких вариаций, интенсивность микросейсм остаётся нестабильной, что в значительной мере связано с внешними атмосферными воздействиями на земную поверхность.

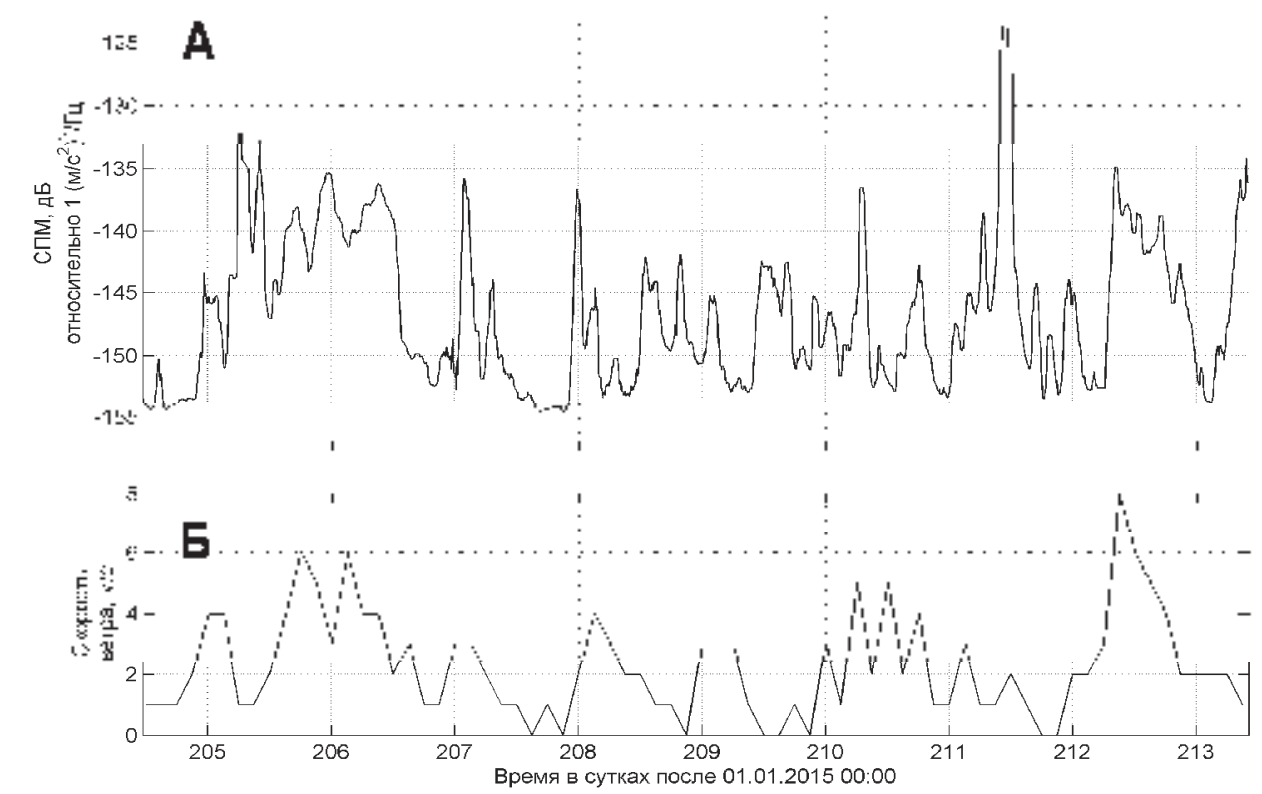

Рис. 3. А - изменение среднего значения спектральной плотности мощности (частоты 2-16 Гц,

X-канал); Б - изменение скорости ветра на метеостанции в п. Богородское

Для изучения возможности получения стабильных оценок интенсивности микросейсм была проанализирована зависимость дисперсии микросейсмического сигнала в частотном диапазоне 0.03-15 Гц от продолжительности интервала оценки (рис. 4). 


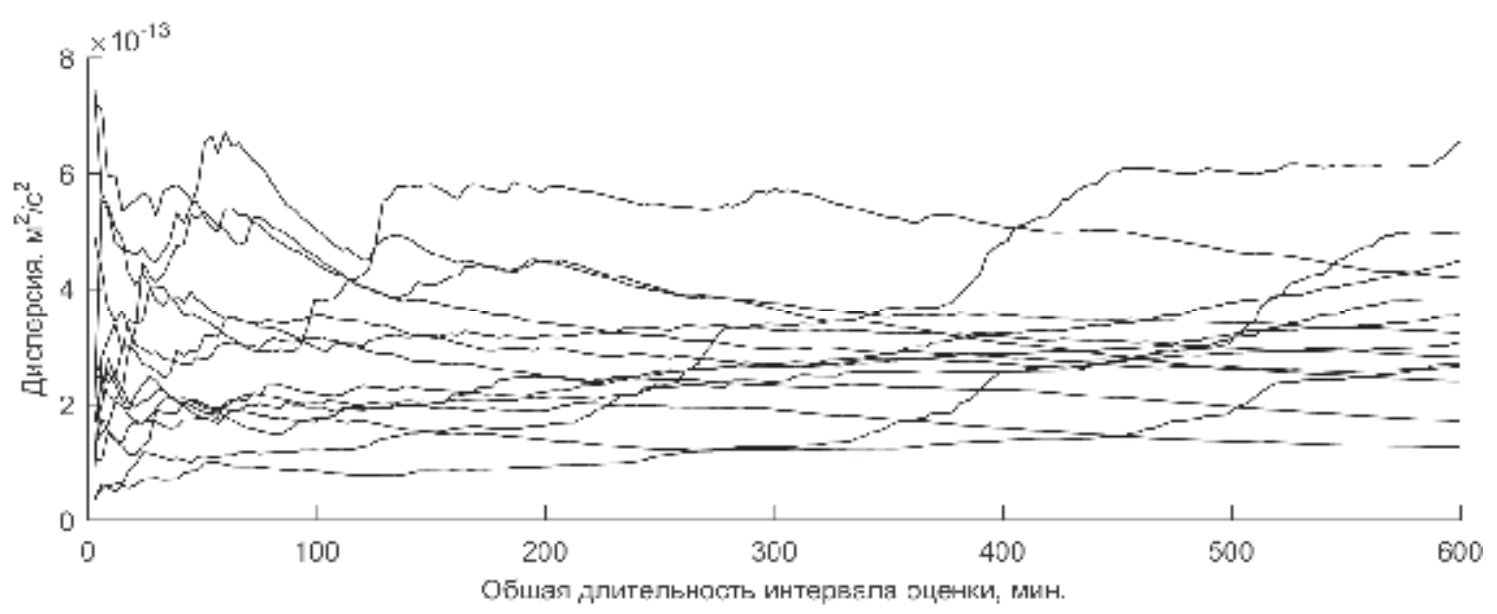

Рис. 4. Зависимость дисперсии микросейсмического сигнала от продолжительности интервала оценки (частотный диапазон 0.03-15 Гц)

Хотя при увеличении длительности интервала оценки дисперсия не стабилизируется (наблюдаются равномерный спад или подъём), у большинства кривых имеется участок относительной стабилизации при длительностях интервала до 100 мин. Таким образом, для определения параметров микросейсмических сигналов (амплитуды и спектрального состава) не следует использовать длительные (больше нескольких часов) записи. В работе [2] было показано, что стационарность оценок параметров микросейсмических сигналов зависит от частоты и составляет от нескольких секунд (для высоких частот) до полутора часов (для низких частот). Этот факт ограничивает возможности геологической интерпретации параметров микросейсмического поля [1].

\section{Список литературы:}

1. Горбатиков А.В. Возможность оценки параметров геологических объектов на основе использования фонового микросейсмического поля. Результаты экспериментальных исследований и моделирование. // Современные методы обработки и интерпретации сейсмологических данных. Материалы международной сейсмологической школы. - Обнинск: ГС РАН, 2006. С. 66-71.

2. Горбатиков А.В., Степанова М.Ю. Результаты исследований статистических характеристик и свойств стационарности низкочастотных микросейсмических сигналов // Физика Земли. - 2008. - № 1. - С. 57-67.

3. Колотова Л.Г., Пупатенко В.В., Рябинкин К.С. Использование MatLab для спектрально-временного анализа слабых землетрясений системы разломов Тан Лу // Современные методы обработки и интерпретации сейсмологических данных. Материалы Десятой Международной сейсмологической школы. Новханы, 14-18 сентября 2015 г. / Отв. ред. Маловичко А.А. - Обнинск: ГС РАН, 2015. С. 199-203.

4. Колотова Л.Г., Харитонов М.Е., Пупатенко В.В., Рябинкин К.С. Спектральный состав микросейсм до и после слабых землетрясений Тан Лу // Материалы Международной конференции «Геолого-геофизическая среда и разнообразные проявления сейсмичности». Нерюнгри, 23-25 сентября 2015 г. - Нерюнгри: Изд-во Технического института (ф) СВФУ, 2015. C. 155-161. DOI:10.18411/svfu1230915-21.

5. Рябинкин К.С., Пупатенко В.В. Спектральный анализ микросейсм и пространственная модель микроземлетрясений Северо-восточного сегмента системы разломов Тан-Лу // Успехи современного естествознания. - 2016. - № 10. - С. 162-166. 
6. Трофименко С.В. Моделирование в теории случайных процессов средствами Excel. - Нерюнгри: Изд-во технического института, 2007. 78 с.

7. Трофименко С.В. Методы и примеры статистических оценок временных рядов. - Нерюнгри: Изд-во Технического института (ф) СВФУ, 2012. 81 с.

8. Трофименко С.В., Гриб Н.Н. Элементы математических моделей в теории и практики случайных процессов. - Нерюнгри: Изд-во Технического института (ф) СВФУ, 2013. 194 с.

9. Трофименко С.В., Рябинкин К.С., Пупатенко В.В. Изучение спектров микросейсм до и после землетрясений // Успехи современного естествознания. - 2016. - № 11-1. - C. 191-196.

11. Beauduin R. et al. The effects of the atmospheric pressure changes on seismic signals or how to improve the quality of a station // Bulletin of the Seismological Society of America. - 1996. - V. 86. - N. 6. - P. 1760-1769.

12. Demuth A., Ottemöller L., Keers H. Ambient noise levels and detection threshold in Norway // Journal of Seismology. - 2016. - V. 20. - N. 3. - P. 889-904. DOI: 10.1007/s10950-016-9566-8

13. Peterson J. Observations and modeling of seismic background noise. USGS OpenFile Report 93-322 / Albuquerque: U.S. Geological Survey, 1993. 94 p.

\section{Разработка мультимедийных практических работ к урокам окружающего мира в начальной школе посредством языка программирования ACTIONSCRIPT}

\section{Саввинов Е.В., студент, Вилюйский педагогический колледж им. Н.Г. Чернышевского, 2. Вилюйск E-mail: Lenal_mrd@mail.ru}

Научные руководители: Лебедева Л.А., Петрова И.И.

Новые информационные технологии имеют огромный диапазон возможностей для совершенствования учебного процесса, в том числе и на уроках Окружающего мира в начальной школе. Одним из дидактических средств, обладающих значительным развивающим потенциалом, является мультимедиа, которые можно использовать на практических занятиях, так как их использования значительно расширяет интенсивность и возможности современного урока, повышает интерес детей.

Проблема заключается в противоречиях между потребностью ИКТсопровождения практических занятий на уроках окружающего мира в начальной школе и отсутствием эффективных материалов вследствие трудоемкости и невозможности разработки сопровождения самими учителями начальных классов.

Цель: разработка мультимедийных практических работ к урокам окружающего мира в начальной школе с помощью языка программирования ACTION SCRIPT.

Данная работа предназначено для учащихся муниципального бюджетного общеобразовательного учреждение «Вилюйская начальная школа №1» муниципального района «Вилюйский улус (район)» Республика Саха (Якутия). 